\title{
DIGITALCOMMONS

$10-1-2011$

\section{Social Goals in Urban Physical Education: Relationships with Effort and Disruptive Behavior}

\author{
Alex C. Garn \\ Louisiana State University \\ Nate McCaughtry \\ Wayne State University, aj4391@wayne.edu \\ Bo Shen \\ Wayne State University, av4286@wayne.edu \\ Jeffrey J. Martin \\ Wayne State University, aa3975@wayne.edu \\ Mariane Fahlman \\ Wayne State University, aa1673@wayne.edu
}

\section{Recommended Citation}

Garn, A.C., McCaughtry, N., Shen, B., Martin, J., \& Fahlman, M. (2011). Social goals in urban physical education: Relationships with effort and disruptive behavior. Journal of Teaching in Physical Education, 30(4), 410-423.

Available at: http://digitalcommons.wayne.edu/coe_khs/31 


\title{
Social Goals in Urban Physical Education: Relationships with Effort and Disruptive Behavior
}

\author{
Alex C. Garn \\ Louisiana State University
}
Nate McCaughtry, Bo Shen, Jeffrey J. Martin, Mariane Fahlman Wayne State University

\begin{abstract}
This study investigated the relationships among four distinct types of social goals, effort, and disruptive behavior in urban physical education. Social responsibility, affiliation, recognition, status goals, along with effort and disruptive behavior in physical education were reported by high school physical education students $(N$ $=314$ ) from three urban schools. Findings from correlation and structural equation modeling analyses revealed that social responsibility goals had a positive relationship with effort and an inverse relationship with disruptive behavior. Social status goals demonstrated a positive relationship with disruptive behavior and no relationship with effort. Social recognition goal results were mixed, as they had positive relationships to both effort and disruptive behavior while social affiliation goals were unrelated to effort or disruptive behavior. Application of these results suggests that physical educators who are able to identify the diverse social motives that underlie students' goals can maximize learning opportunities by increasing student effort and minimizing disruptive behavior.
\end{abstract}

Keywords: achievement motivation, adolescents, classroom involvement

Disruptive behavior is a common concern for all teachers in all subjects. This topic, however, gets extra attention in schools that serve minority students living in poverty (Pellerin, 2005). Specifically, disruptive behavior is often identified by urban teachers as one of the major barriers to both teaching and learning. Students who are disruptive in physical education (PE) can reduce learning and physical activity opportunities for themselves and other students (Supaporn, Dodds, \& Griffin, 2003). Disruptive students can also create stress and dissatisfaction for

Garn is with Louisiana State University, Kinesiology, Baton Rouge, LA. McCaughtry, Shen, Martin, and Fahlman are with Wayne State University, Center for School Health and Division of Kinesiology, Health, \& Sport Studies, Detroit, MI. 
PE teachers (McCaughtry, Barnard, Martin, Shen, \& Kulinna, 2006; McCormack, 1997). Research on disruptive behavior in PE has traditionally focused on teachers' perceptions (e.g., Ennis, 1995; Fink \& Siedentop, 1989; Placek, 1983). Cothran, Kulinna, and Garrahy (2009) recently noted that surprisingly little research has considered disruptive behavior from students' point of view in PE. Students in their study reported that disruptive behavior in many cases stemmed from a lack of motivation.

Effort, on the other hand, maximizes students' learning potential and physical activity opportunities. Students who try hard in PE rarely disrupt other students, move beyond basic compliance, and engage with content at high levels (Rink, 2010). Student effort in PE is also a key ingredient in the development of self-regulation skills (Hellison, 2003) and closely linked to intrinsic motivation (Ntoumanis, 2001). In plain terms, students who demonstrate high levels of effort and low levels of disruptive behavior can benefit most from PE classes. Students who are disruptive and put forth little effort are likely to get into trouble, waste time, and get little out of PE classes.

Effort and disruptive behavior, together, can provide a thorough picture of students' classroom involvement (Kiefer \& Ryan, 2008). A review of the PE literature suggests that most researchers investigate these student outcomes separately using different theoretical constructs and methodologies. For example, effort in $\mathrm{PE}$ is a student outcome generally examined quantitatively within motivational frameworks (Agbuga \& Xiang, 2008; Garn \& Sun, 2009; Guan, Xiang, McBride, $\&$ Bruene, 2006). These studies use achievement goal theory to showcase a significant positive relationship between goals and effort based on questionnaire data from hundreds of secondary PE students. Disruptive behavior on the other hand is an outcome commonly framed in effective teaching or ecological systems theories and use qualitative methods and/or descriptive statistics (Carlson, 1995; Carlson \& Hastie, 1997; Supaporn et al., 2003). These studies provide in-depth accounts of how teacher behaviors and/or social interactions/relationships (teacher-student; student-student) impact student disengagement in a small number of cases. Finding ways to bridge results across these two different paradigms could help synergize classroom involvement literature in PE.

\section{Social Goals}

Incorporating a social goals framework is one bridging strategy that could produce greater understanding of classroom involvement. A social goals framework places social constructs at the forefront, similar to ecological studies focusing on disruptive behavior (Supaporn et al., 2003), and emphasizes goals, a staple of motivational studies focusing on effort (Agbuga \& Xiang, 2008). Motivational theorists suggest that goals exert a powerful influence on engagement and behaviors in and out of schools (Dweck, 1986; Locke \& Latham, 2002; Wentzel, 2005). Locke and Latham (2002) define goals as cognitive based aims of future desired outcomes and suggest that goals influence behavior by (a) focusing attention on goal related activities, (b) energizing effort, (c) extending persistence, and (d) stimulating arousal, discovery, and goal relevant knowledge.

In this study, social goals reflect a student's desired outcomes in relation to interactions with other students and teachers (Wentzel, 2005). With the social 
nature of PE, students can pursue an array of different social goals that are likely to affect their classroom involvement. For example, students may aim to affiliate with peers (Allen, 2005), gain friendships (Nelson \& DeBacker, 2008), dominate other students (Kiefer \& Ryan, 2008), or demonstrate social responsibility (Wentzel, 1991). Determining what types of social goals are associated with maximum effort and minimal disruptive behaviors could help urban PE teachers engage their students at higher levels.

\section{Peer Relationship Goals}

Ryan (2000) reports that choices about engagement, motivation, commitment, and achievement in schools are influenced by students' perceptions of peer relationships. Surprisingly, relatively few investigations have focused on peer-related social goals within PE contexts, despite the significant amount of time that students spend interacting with peers (Garn \& Sun, 2009; Garn, Ware, \& Solmon, 2011; Gonzalez-Cutre, Sicilia, Moreno, \& Fernandez-Balboa, 2009; Guan, McBride, \& Xiang, 2006; Guan, Xiang, McBride, \& Bruene, 2006; Solmon, 2006). A general social relationship goal has been implemented most often in these previous social goal studies (Gonzalez-Cutre et al., 2009; Guan, McBride et al., 2006. Guan, Xiang et al., 2006; Solmon, 2006). Guan and colleagues define social relationship goals as "an individual's desire to form and maintain positive peer relationships in schools" (Guan, McBride et al., 2006, p. 227).

In a predominantly African American sample (i.e., 80\%), Solmon (2006) revealed that social relationship goals had a significantly higher mean score than other types of achievement goals in PE. Gonzalez-Cutre et al. (2009) linked social relationship goals to perceived competence and dispositional flow with Spanish PE students. Guan, Xiang et al. (2006) examined the relationship that social relationship goals had with high school students' effort/persistence in PE and reported a nonsignificant association. The lack of goal specificity using a broad approach to conceptualize social relationship goals may limit researchers' ability to predict outcomes or establish relationships. Many goal theorists argue that social goal specificity is important, especially for adolescents because it is common for them to strive for a variety of social connections in physical activity settings. (Allen, 2005; Stuntz \& Weiss, 2009).

In this study, three different social goals are used to reflect peer relationships: social affiliation, social recognition, and social status (Allen, 2005). Social affiliation goals indicate an individual's desire to develop reciprocal relationships and pursue social opportunities via participation in physical activity. Social status goals reflect an individual's desire to increase peer group standing. Social recognition goals focus on a student's aim to gain peer recognition based on her/his physical abilities. Although Allen's framework of social goals was originally developed for adolescents involved in sports, these three specific types of social relationship goals represent common strivings for students in high school PE (Garn et al., 2011). Garn et al. revealed that social status, social recognition, and social affiliation goals all had small to moderate positive correlations with effort in PE: however, in their regression model only social status goals maintained a significant relationship with effort. It is currently unclear how these different types of social relationship goals might be associated with disruptive behavior. Allen (2005) suggests that 
social affiliation goals are generally considered the most adaptive because of the importance of establishing meaningful relationships whereas social status and social recognition goals focus more on validation, which can lead to adaptive outcomes if fulfilled and maladaptive outcomes if unfulfilled.

\section{Social Responsibility Goals}

Social responsibility goals reflect a student's desire to follow social rules and expectations in the classroom (Guan, McBride et al., 2006; Wentzel, 1991). In past research social responsibility goals have stronger links to positive outcomes in PE such as effort/persistence (Guan, Xiang et al., 2006) and perceived competence (Gonzalez-Cutre et al., 2009) than social relationship goals. Social responsibility goals have also been linked to positive academic outcomes (Wentzel, 1991) and psychological well-being (Anderman, 2003). Social responsibility goals place more emphasis on a student's relationships with the teacher and the value that he/she places in the learning climate of the classroom. Guan, Xiang et al. (2006) found a robust relationship $(\beta=.47)$ between social responsibility goals and effort/persistence in high school PE. Theoretically, social responsibility goals should have a positive relationship with effort because this is a common expectation that PE teachers have of their students and an inverse relationship with disruptive behavior because students who strive to follow social rules and expectations are more likely to help establish safe classroom environments, interact effectively with teachers and peers, and experience academic success (Wentzel, 2005). Empirical evidence of the relationship between social responsibility goals and disruptive behavior in $\mathrm{PE}$ is currently absent.

\section{Gender}

Although gender is not the major focus of the current study, researchers have suggested that students' social goals reports can vary by gender. For example, female students reported higher levels of social intimacy goals (similar to social affiliation goals) than males while males report higher levels of social status goals in an academic setting (Ryan, Hicks, \& Midgley, 1997). More recently, female students in high school PE reported higher social responsibility and social relationship goals compared with male students (Guan, Xiang et al., 2006). Past research has also supported the possibility of gender differences in reports of disruptive behavior and effort. For example, Cothran and Kulinna (2007) found that males and females viewed disruptive behavior differently. Specifically, females perceived disruptive behavior to occur more often in PE than males. Although effort has not varied by gender in past social goals research (Garn \& Sun, 2009; Guan, Xiang et al., 2006), this type of exploration has not been examined in urban PE contexts. Ennis (1999) identified a number of engagement barriers that girls face in urban PE. Therefore, investigating the relationships among gender, social goals, and classroom involvement in PE are currently needed.

In summary, the current study explored the relationships among diverse social goals, effort, and disruptive behavior in urban PE. A secondary focus investigated possible gender differences among the study variables. The major research question examined was: what effects do social goals have on students' effort and disruptive 
behavior in urban PE? To date, only Solmon (2006) has investigated social goals in an urban, predominately African American high school PE context. This study adds to Solmon's work in the urban context. Findings from this study also provide a link between classroom involvement research that has independently examined disruptive behavior and student effort in PE.

\section{Method}

\section{Participants and Setting}

Student participants were three-hundred and fourteen (173 male, 141 female) high school students involved in PE from three urban schools in the Midwestern United States. The mean age of the participants was $15.47(S D=1.16)$. Over 94\% of the students identified their ethnicity as Black/African American and approximately $80 \%$ of the students were in 9 th or 10th grades. The high schools were situated in a major inner city school district facing, arguably, the greatest economic depression (U.S. Census Bureau, 2008) and the highest dropout rates (Swanson, 2008) in the United States. The curriculum at all three schools blended a personal conditioning, fitness- based approach with large-side team sports taught using a multiactivity format. All three teachers were experienced, having accumulated between 14-25 years of teaching PE in the urban, inner-city district.

\section{Measures}

Social Goals. The Social Motivational Orientation in Sport Scale (SMOSS) developed by Allen (2005) was used to measure social affiliation goals ( 7 items), social status goals (3 items), and social recognition goals (4 items). The only modification made was changing the stem from "I feel things have gone really well for me in sport when..." to "I feel things have gone really well for me in PE class when..." An example of a social affiliation goal item is "I have fun with others in my PE class." An example of a social status goal item is "I am the center of attention" while an example of a social recognition goal item is "I receive recognition from others about my accomplishments." The SMOSS was measured on a five-point scale from 1 (strongly disagree) to 5 (strongly agree). The SMOSS has demonstrated validity and reliability with adolescent populations in sport (Allen, 2005) and high school PE (Garn et al., 2011).

The Social Goals Scale-Physical Education (SGS-PE) was used to measure social responsibility goals (Guan, McBride et al., 2006). The social responsibility subscale of the SGS-PE consists of five items (e.g., "I do what the PE teacher asks me to do"). These items were measured on a scale ranging from 1 (strongly disagree) to 5 (strongly agree). The social responsibility goals subscale has yielded valid and reliable results with high school students in PE (Guan, McBride et al., 2006; Guan, Xiang et al., 2006).

Student Reported Effort. Four items were borrowed from Guan, Xiang et al. (2006) to measure students' self-reported effort toward PE. Each item (e.g., I work hard to do well even if I don't like what we are doing in PE) was measured on a 5-point scale ranging from 1 (not at all like me) to 5 (completely like me). 
This scale has been used on multiple occasions in previous PE research and demonstrated sound psychometric properties (Garn \& Sun, 2009).

Disruptive Behavior. Student disruptive behavior was measured with the disruptive behavior subscale from the Patterns for Adaptive Learning Scales (PALS; Midgley et al., 2000). Five items (e.g., I sometimes behave in a way that upsets my teacher during PE class) were answered on a five point scale ranging from 1 (strongly disagree) to 5 (strongly agree). Midgley and colleagues provide comprehensive evidence for the validity and reliability of all PALS subscales with adolescents.

\section{Procedure}

Permission was granted by the University Institutional Review Board, school district, teachers, students, and their parents to conduct the study. A research assistant, with prior data collection experience, was trained to administer the surveys. Specifically, the research team went over each survey with the research assistant to ensure that he was familiar with the content and would be able to answer students' potential questions effectively. The research team also modeled survey administration to the research assistant before data collection. The research assistant visited PE classes, explained the study/surveys, ensured the students there were no right or wrong answers, and highlight that their results would remain anonymous. The students completed the surveys in approximately $30 \mathrm{~min}$ while the research assistant answered individual questions and monitored the students.

\section{Data Analysis}

Data were screened and assumptions tests were conducted. Means, standard deviations, and Pearson correlation coefficients were calculated. A multivariate analysis of variance (MANOVA) was used to investigate mean level differences by gender for the variables of this study. Finally, structural equation modeling (SEM) with maximum likelihood estimation procedures was used to examine the relationships among social goals, effort, and disruptive behavior. SEM uses a two-step approach that consists of establishing a measurement model of indicators for proposed latent variables through confirmatory factor analysis (CFA) followed by testing the hypothesized structural relationships (i.e., full structural model) among the latent variables via path analysis (Byrne, 2001). In the full structural model, the exogenous latent variables (i.e., independent) were social status goals ( 3 indicators), social responsibility goals ( 5 indicators), social affiliation goals ( 7 indicators), and social recognition goals (4 indicators) while the endogenous latent variables (i.e., dependent) were effort (4 indicators) and student disruptive behavior (5 indicators). Exogenous variables were allowed to correlate.

The measurement model was evaluated using criteria outlined by $\mathrm{Hu}$ and Bentler (1999). The overall fit of the model was asses by examining the $\chi^{2}$ to degree of freedom $(d f)$ ratio $\left(\right.$ good fit $=\chi^{2} / \mathrm{df}$ ratio $\leq 2.00$; acceptable fit $=\chi^{2} / \mathrm{df}$ ratio $\left.\leq 3.00\right)$. The comparative fit index (CFI), Tucker-Lewis Index (TLI) and the root mean square error of approximation (RMSEA) were also used to examine the fit of the data to the proposed model. A good fit for the CFI and TLI are .95 or above while scores of .90-.94 are considered acceptable. A good fit for RMSEA is .06 or lower while 
scores between .08 and .10 are deemed acceptable. Standardized path coefficients and squared multiple correlations were used to evaluate the full structural model.

\section{Results}

\section{Descriptive Statistics and Simple Correlations}

Means, standard deviations, Pearson correlation coefficients, and Cronbach's alpha reliability estimates are presented in Table 1. Mean scores for social goals ranged from a low of 3.05 ( $S D=.92$ (social status goals) to a high of 3.89 ( $S D=.74$ (social responsibility goals) on the five point scale. Reliability scores ranged from .78-.93 and were therefore deemed adequate (Nunnally, 1978). The four types of social goals had small to moderate positive correlations among each other. All four social goals also had positive relationships with student effort. Social responsibility goals had an inverse association with disruptive behavior (i.e., greater social responsibility goals $=$ lower levels of disruptive behavior), while social status goals and social recognition had positive relationships with disruptive behavior. Social affiliation goals were unrelated to disruptive behavior.

\section{MANOVA}

A significant Box M test $(F=1.56, p<.05)$ suggested the test for homogeneity of variance-covariance was not met. Therefore, Pillia's Trace was used because the test is considered robust under these circumstances (Tabachnick \& Fidell, 2007). Results from MANOVA revealed an overall main effect for gender, Pillia's Trace $=.18, F(6,307)=11.67, p<.01, \mathrm{XXX}^{2}=.18$. Follow-up univariate tests revealed mean level differences for social responsibility goals, $F(1,312)=4.63, p<.05$, $\mathrm{XXX}^{2}=.02$, social status goals, $F(1,312)=23.37, p<.01, \mathrm{XXX}^{2}=.07$, social recognition goals, $F(1,312)=9.89, p<.01, \mathrm{XXX}^{2}=.03$, effort, $F(1,312)=$ $14.97, p<.01, \mathrm{XXX}^{2}=.05$, and disruptive behavior, $F(1,312)=16.90, p<.01$,

\section{Table 1 Descriptive Statistics, Reliability Estimates, and Simple Correlations for Study Variables}

\begin{tabular}{|c|c|c|c|c|c|c|c|c|c|}
\hline & & $M(S D)$ & $\alpha$ & 1 & 2 & 3 & 4 & 5 & 6 \\
\hline 1. & Status & $3.05(.92)$ & .78 & 1.00 & & & & & \\
\hline 2. & Responsibility & $3.89(.74)$ & .82 & $.13^{*}$ & 1.00 & & & & \\
\hline 3. & Affiliation & $3.88(.69)$ & .86 & $.40 * *$ & $.48 * *$ & 1.00 & & & \\
\hline 4. & Recognition & $3.60(.83)$ & .85 & $.49 * *$ & $.47 * *$ & $.57 * *$ & 1.00 & & \\
\hline 5. & Effort & $3.70(.89)$ & .82 & $.28 * *$ & $.41 * *$ & $.35^{* *}$ & $.52 * *$ & 1.00 & \\
\hline 6. & D Behavior & $1.94(1.12)$ & .93 & $.24 * *$ & $-.28 * *$ & .05 & $.27 * *$ & .04 & 1.00 \\
\hline
\end{tabular}

Note. $M=$ mean; $S D=$ standard deviation; $\alpha=$ Cronbach alpha; Status = social status goals $;$ Responsibility = social responsibility goals; Recognition = social recognition goals; Effort = student effort in PE;

$\mathrm{D}$ Behavior $=$ student reported disruptive behavior in PE.

. $*=p<.05 ; * *=p<.01$. 
$\mathrm{XXX}^{2}=.05$. There were no gender differences for the social affiliation goal, $F$ $(1,312)=.08, p=.78, \mathrm{XXX}^{2}=.00$. Males reported higher levels of social status goals, social recognition goals, effort, and misbehavior. Females reported higher levels of social responsibility goals. The effect sizes in all follow-up tests were considered small (Cohen, 1992).

\section{SEM}

Final results of the $S E M$ are provided in Figure 1. The measurement model of the SEM supported the fit of the model to the data. Specifically, the $\chi^{2} / \mathrm{df}$ ratio $(594.52$ $/ 309)=1.92 ; \mathrm{CFI}=.94 ; \mathrm{TLI}=.92 ; \mathrm{RMSEA}=.05$ met the criteria outlined by Hu and Bentler (1999). Examination of the standardized factor loadings suggested that all items were significant except for one item from the social responsibility goals subscale ("I do not distract a classmate when he/she is performing an individual activity"), so it was removed (Ford, MacCallum, \& Tait, 1986). Findings from the full structural model yielded support for the relationships between social goals and the outcome variables. Specifically, social responsibility $(\beta=.21)$ and social recognition $(\beta=.53)$ goals were positive predictors of student effort accounting for $41 \%$ of the variance. Social affiliation $(\beta=-.07)$ and social status $(\beta=.04)$ goals were not significant predictors of effort. Social responsibility $(\beta=-.44)$ and social status $(\beta=.20)$ goals were significant predictors of disruptive behavior, accounting for $20 \%$ of the variance. Social affiliation $(\beta=.05)$ and social recognition $(\beta=$ $.17)$ goal were not significant predictors of disruptive behavior. In general, social responsibility goals had the most adaptive relationship student involvement (i.e., high effort, low disruptive behavior) while social status goals had the least adaptive relationship with student involvement.

\section{Discussion}

Both effort and disruptive behavior are key ingredients in determining students' classroom involvement. The aim of this study, therefore, was to investigate relationships among four diverse social goals, effort, and disruptive behavior in urban PE.

Stuntz and Weiss (2009) advocate for measuring diverse social goals in physical activity environments; however, this is one of the first studies to move beyond a two social goals approach in PE (Garn \& Sun, 2009; Guan, McBride, et al., 2006). Moderate correlations among the four different social goals revealed expected interrelationships (Allen, 2005), but does not suggest that the social goals subscales tapped the same construct. Support of the psychometric properties (i.e., internal consistency estimates, SEM measurement model) for the diverse set of social goals provides a comprehensive framework for future studies to further explore social goals in urban PE contexts.

\section{Relationships among Social Goals and Classroom Involvement}

Findings from this study highlight both the adaptive and maladaptive relationships that social goals have with classroom involvement in urban high school PE. Social responsibility goals had the most adaptive associations with classroom involvement. 


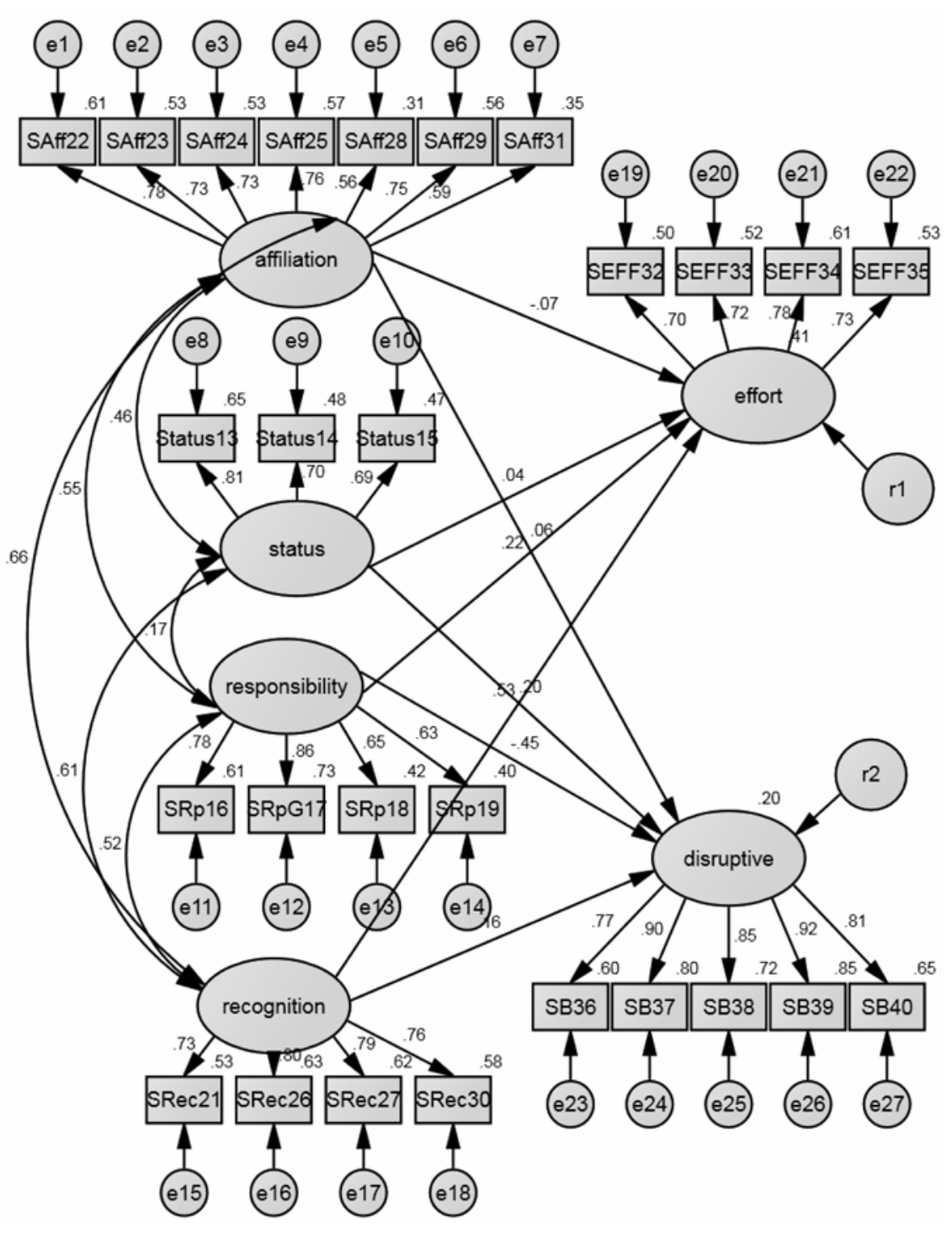

Figure 1 - Structural equation modeling results with significant standardized path coefficients are presented above. Affiliation = social affiliation goals; Status = social status goals; Responsibility = social responsibility goals; Recognition $=$ social recognition goals; Disruptive $=$ student reported disruptive behavior in PE. Fit indices for the model $\chi^{2} / \mathrm{df}$ ratio $(594.52 / 309)=1.92 ; \mathrm{CFI}=.94 ; \mathrm{TLI}=.92 ; \mathrm{RMSEA}=.05$. Multiple squared correlation for effort $=.41$ and disruptive behavior $=.20$. 
Specifically, students who adopted social responsibility goals were less likely to create management problems and more likely to be engaged at a high level. The positive relationship between social responsibility goals and student effort in the correlation and SEM reflects findings from previous studies in high school PE (Guan, Xiang et al., 2006). The association and predictive utility of social responsibility goals on lower levels of student disruptive behavior has not been identified in previous classroom involvement literature in $\mathrm{PE}$ and provides an initial link between studies focusing on effort (Garn \& Sun, 2009) and disruptive behavior (Supaporn et al., 2003) separately. Taken together, physical educators who create a learning environment that allows students to internalize the importance of following classroom expectations are likely to have classes that are not only compliant, but highly engaged, which is a condition necessary for learning (Rink, 2010). In fact, Wentzel (1991) theorized and provided evidence of the importance social responsibility has on students' development of intellectual and social competence.

Social status goals had the least adaptive relationship with classroom involvement in this urban PE context. This finding supports past research in academic settings that have also revealed the negative effects of social status goals (Ryan et al., 1997). However, social status goals have been linked positively to effort in a suburban high school PE context (Garn et al., 2011). In the current settings, putting forth effort in PE may have been viewed as a less socially desirable strategy to increasing visibility within one's peer group of choice. In fact, the positive path between social status goals and disruptive behavior in the SEM suggested that acting out was viewed as a more viable option for fulfilling students' social status goals. It is important to understand why these students felt status goals were best met through low (i.e., low effort, high disruptive behavior) and not high (i.e., high effort, low disruptive behavior) classroom involvement, especially since adolescents are highly aware of fitting into the right peer groups (Wentzel, 2005). Large-sided games were a curricular focus across the three schools making PE a very public environment in which students put their level of effort on display. Thus, it may have been easier (and safer) for students to gain approval from the right peer group through disruptive behavior than risk social capital by trying hard and failing. Implementing small-sided games and stressing personal improvement may help reduce the negative effects of social status goals.

Social recognition goals had the most complex relationship with students' classroom involvement. Predictive utility for effort and bordering significance for disruptive behavior $(p=.12)$ suggests that students perceived themselves to receive physical ability recognition from peers for both high and low levels of class involvement. We hypothesize that students would be more apt to fulfill social recognition goals through effort during activities that balance challenge and success. For example, students may not receive ability recognition for trying hard during an easy activity. On the other hand, if an activity is too difficult, students might receive negative recognition if they tried hard and were unsuccessful. In both cases, the social recognition goal would remain unfulfilled. It is not uncommon for high school students in PE to have extensive exposure to activities that are motor inappropriate (Hastie, 1994). In such cases, disruptive behavior may provide a more attractive outlet for the fulfillment of students' social recognition goals in PE.

Social affiliation goals did not contribute to the predictive variance of effort or disruptive behavior. That is, pursuing goals to engage in reciprocal social 
opportunities had no association with students trying hard or causing disruptions in PE classes. It is possible that social affiliation goals relate to specific social outcomes such as quality friendships (Wentzel, 2005). Social affiliation goals may be linked to classroom involvement indirectly by enhancing psychological well-being (Ryan \& Shim, 2008).

Although the effect sizes were small, results from MANOVA revealed mean level differences by gender across the diverse social goals investigated in this study except social affiliation goals. Girls had higher levels of social responsibility goals compared with boys while the reverse was true for social status and social recognition goals. Allen (2005) reports that both social status and social recognition have close ties with obtaining validation in social relationships. These results align to the social construction of gender and common gender stereotypes often perpetuated in PE (Kirk, 2003). Boys are often socialized on the importance of being recognized as highly skilled in PE while girls are socialized to be cooperative and follow the rules. It is common for girls who are highly skilled in PE to be validated in male terms (e.g., you ran as fast as the boys), given stereotypical labels (e.g., tomboy), or even be ostracized (e.g., harassed / sexuality questioned). The social construction of gender in PE could also explain the higher reports of effort and disruptive behavior from the boys. That is, boys could have exerted more effort in PE than girls during the pursuit of meeting expectations to be highly skilled. Girls, on the other hand, could have been less disruptive because they were socialized to be compliant. These results support previous literature that suggest boys and girls view disruptive behavior in PE differently (Cothran \& Kulinna, 2007) and girls tend to be less engaged than boys in the urban PE (Ennis, 1999).

\section{Implication for Urban Physical Educators}

Because students' social responsibility goals had the most adaptive relationships with classroom involvement, it would be advantageous for urban physical educators to find ways to promote social responsibility goals. Currently, only one study in PE has explored this issue. Gonzalez-Cutre et al. (2009) revealed that a task-involved motivational climate has a positive association with social responsibility goals. This association would suggest that PE teachers in the urban context who follow the TARGET principles (Ames, 1992) could potentially facilitate social responsibility goals. Other environmental factors that future research should explore include PE curriculum that emphasizes social responsibility (Hellison 2003).

Our results suggest that urban physical educators and students need to have a clear understanding of behavioral expectations and norms in PE. We advocate for a reciprocal communication process that involves input from both students and teachers. Disruptive behavior is a strong predictor of future dropout in urban schools (Balfanz, Herzog, \& Mac Iver, 2007). With one of the highest dropout rates in the United States (Swanson, 2008), it seems especially important for students and teachers in this urban school district to work together in establishing behavioral expectations and norms that builds an atmosphere of mutual support. This type of atmosphere could develop a stronger sense of student commitment to PE and possibly even school in general.

The relationship between social recognition goals and students' effort suggests that urban physical educators could benefit from developing a class environment that 
promotes explicit appreciation for diverse skill levels. Emphasizing task mastery and personal improvement could be an effective strategy for promoting social recognition goals through effort for students who are not highly skilled. We advocate that PE teachers do their best to get to know the unique academic, physical, and social characteristics of individual students in each class and use this understanding as a guide for creating a productive learning environment (Shulman, 1986).

Gender differences in social goals, effort, and disruptive behavior followed typical stereotypes within the social construction of gender. It would behoove urban physical educators to be aware of practices that reinforce traditional masculine and feminine roles based on sex alone. Matching experiences in PE with students" individual preferences instead of assuming that "boys" or "girls" do not like certain activities is one example that could potentially reduce gender stereotypes. Other examples that could reduce gender stereotypes include providing a balanced masculine/feminine curriculum and having similar effort and behavior expectations for all students.

\section{Conclusions and Limitations}

We acknowledge limitations to the current study. The correlational, retrospective design of this study does not allow for casual inferences to be made. Future research would benefit from prospective and longitudinal research designs. Relying completely on self-report data from students is also a limitation. Measuring disruptive behavior with systematic observation techniques in future research could strengthen the current findings of this study. Along the same lines, measuring effort and disruptive behavior from both student and teacher perspectives could make a significant contribution to future research. Despite these limitations, this study adds to the understanding of classroom involvement in urban PE. Findings highlight the important relationships between social goals and the levels of engagement in PE from the students' points of view. This study is one of the few that examines two levels of classroom involvement (i.e., effort and disruptive behavior). Findings suggest that teachers who are able to identify students' underlying social motives and create learning environments that support responsibility goals and reduce social status goals can maximize students' effort and may reduce disruptive behavior. This type of student engagement is essential for learning in PE (Rink, 2010).

\section{References}

Agbuga, B., \& Xiang, P. (2008). Achievement goals and their relations to self-reported persistence/effort among Turkish students in secondary physical education. Journal of Teaching in Physical Education, 27, 179-191.

Allen, J.B. (2005). Measuring social motivational orientations in sport: An examination of the construct validity of the SMOSS. International Journal of Sport and Exercise Psychology, 3, 147-161.

Ames, C. (1992). The relationship of achievement goals to student motivation in classroom settings. In G. Roberts (Ed.), Motivation in sport and exercise (pp. 161-176). Champaign, IL: Human Kinetics.

Anderman, L.H. (2003). Academic and social perceptions as predictors of change in middle school students' sense of school belonging. Journal of Experimental Education, 72, 5-22. 
Balfanz, R., Herzog, L., \& Mac Iver, D.J. (2007). Preventing student disengagement and keeping students on the graduation path in urban middle-grades schools: Early identification and effective interventions. Educational Psychologist, 42, 223-235.

Byrne, B.M. (2001). Structural equation modeling with AMOS: Basic concepts, applications, and programming. Mahwah, NY: Lawrence Erlbaum Associates.

Carlson, T.B. (1995). We hate gym: Student alienation from physical education. Journal of Teaching in Physical Education, 4, 467-477.

Carlson, T.B., \& Hastie, P. (1997). The student social system within sport education. Journal of Teaching in Physical Education, 16, 176-195.

Cohen, J. (1992). A power primer. Psychological Bulletin, 112, 155-159.

Cothran, D.J., \& Kulinna, P.H. (2007). Students' reports of misbehavior in physical education. Research Quarterly for Exercise and Sport, 78, 216-224.

Cothran, D.J., Kulinna, P.H., \& Garrahy, D.A. (2009). Attributions for and consequences of student misbehavior. Physical Education and Sport Pedagogy, 14, 155-167.

Dweck, C.S. (1986). Motivational processes affecting motivation. The American Psychologist, 41, 1040-1048.

Ennis, C.D. (1995). Teachers' responses to noncompliant students: The realities and consequences of a negotiated curriculum. Teaching and Teacher Education, 11, 59-78.

Ennis, C.D. (1999). Creating a culturally relevant curriculum for disengaged girls. Sport Education and Society, 4, 31-44.

Fink, J., \& Siedentop, D. (1989). The development of routines, rules, and expectations at the start of the school year. Journal of Teaching in Physical Education, 8, 198-212.

Ford, J., MacCallum, R., \& Tait, M. (1986). The application of factor analysis in psychology: A critical review and analysis. Personnel Psychology, 39, 291-314.

Garn, A.C., \& Sun, H. (2009). Approach-avoidance motivational profiles in early adolescence to a PACER fitness test. Journal of Teaching in Physical Education, 28, 400-421.

Garn, A.G., Ware, D.R., \& Solmon, M.A. (2011). Student engagement in high school physical education: Do social motivation orientations matter? Journal of Teaching in Physical Education, 30, 84-98.

Gonzalez-Cutre, D., Sicilia, A., Moreno, J.A., \& Fernandez-Balboa, J.M. (2009). Dispositional flow in physical education: Relationships with motivational climate, social goals, and perceived competence. Journal of Teaching in Physical Education, 28, 422-440.

Guan, J., McBride, R.E., \& Xiang, P. (2006). Reliability and validity evidence for the Social Goal Scale-Physical Education (SGS-PE) in high school physical education settings. Journal of Teaching in Physical Education, 25, 226-238.

Guan, J., Xiang, P., McBride, R.E., \& Bruene, A. (2006). Achievement goals, social goals, and students' reported persistence and effort in high school physical education. Journal of Teaching in Physical Education, 25, 58-74.

Hastie, P. (1994). Selected teacher behaviors and students ALT-PE in secondary school physical education classes. Journal of Teaching in Physical Education, 13, 342-359.

Hellison, D. (2003). Teaching personal and social responsibility in physical education. In S.J. Silverman \& C.D. Ennis (Eds.), Student learning in physical education: Applying research to enhance instruction (2nd ed., pp. 241-254). Champaign, IL: Human Kinetics.

Hu, L., \& Bentler, P.M. (1999). Cutoff criteria for fit indexes in covariance structure analysis: Conventional criteria versus new alternatives. Structural Equation Modeling, 6, 1-55.

Kiefer, S.M., \& Ryan, A.M. (2008). Striving for social dominance over peers: The implications for academic adjustment during early adolescence. Journal of Educational Psychology, 100, 417-428.

Kirk, D. (2003). Student learning and the social construction of gender in sport and physical education. In S.J. Silverman \& C.D. Ennis (Eds.), Student learning in physical education: Applying research to enhance instruction (2nd ed., pp. 67-81). Champaign, IL: Human Kinetics. 
Locke, E.A., \& Latham, G. (2002). Building a practically useful theory of goal settings and task motivation. The American Psychologist, 57, 705-717.

McCaughtry, N., Barnard, S., Martin, J., Shen, B., \& Kulinna, P. (2006). Teachers' perspectives on the challenges of teaching physical education in urban schools: The student emotional filter. Research Quarterly for Exercise and Sport, 77, 486-497.

McCormack, A. (1997). Classroom management problems, strategies, and influences in physical education. European Physical Education Review, 3, 102-115.

Midgley, C., Maehr, M.L., Hruda, L.Z., Anderman, E., Anderman, L.H., Freeman, K.E., ... Urdan, T. (2000). Manual for the Patterns for Adaptive Learning Scales. The University of Michigan.

Nelson, R.M., \& DeBacker, T.K. (2008). Achievement motivation in adolescents: The role of peer climate and best friends. Journal of Experimental Education, 76, 170-189.

Ntoumanis, N. (2001). A self-determination approach to the understanding of motivation in physical education. The British Journal of Educational Psychology, 71, 225-242.

Nunnally, J.C. (1978). Psychometric theory. New York: McGraw-Hill.

Pellerin, J.A. (2005). Student disengagement and the socialization style of high schools. Social Forces, 84, 1159-1179.

Placek, J. (1983). Conceptions of success in teaching: Busy, happy, and good? In T. Templin \& J. Olson (Eds.), Teaching in physical education (Big Ten Body of Knowledge Symposium Series, Vol. 14), (pp. 46-56). Champaign, IL: Human Kinetics.

Rink, J.E. (2010). Teaching physical education for learning (6th ed.). Boston, MA: McGraw Hill.

Ryan, A.M. (2000). Peer groups as a context for the socialization of adolescents' motivation, engagement, and achievement in school. Educational Psychologist, 35, 101-111.

Ryan, A.M., Hicks, L., \& Midgley, C. (1997). Social goals, academic goals, and avoiding seeking help in the classroom. The Journal of Early Adolescence, 17, 152-171.

Ryan, A.M., \& Shim, S.S. (2008). An exploration of young adolescents' social achievement goals and social adjustment in middle school. Journal of Educational Psychology, 100, 672-687.

Shulman, L. (1986). Those who understand: Knowledge growth in teaching. Educational Researcher, 15(2), 4-14.

Solmon, M.A. (2006). Goal theory in physical education classes: Examining goal profiles to understand achievement motivation. International Journal of Sport and Exercise Psychology, 4, 325-346.

Stuntz, C.P., \& Weiss, M.R. (2009). Achievement goal orientations and motivational outcomes in youth sport: The role of social orientations. Psychology of Sport and Exercise, $10,255-262$.

Supaporn, S., Dodds, P., \& Griffin, L. (2003). An ecological analysis of middle school misbehavior through student and teacher perspectives. Journal of Teaching in Physical Education, 22, 328-349.

Swanson, C.B. (2008). Crisis in cities: A special analytic report on high school graduation. Retrieved from http://www.americaspromise.org/uploadedFiles/AmericasPromiseAlliance/Dropout_Crisis/SWANSONCitiesInCrisis040108.pdf

Tabachnick, B.G., \& Fidell, L.S. (2007). Using multivariate statistics (5th ed.). Boston, MA: Allyn and Bacon.

United States Census Bureau. (2008). Retrieved September 19, 2010 from http://www. census.gov.cgi-bin/saipe.cgi.

Wentzel, K.R. (1991). Social competence at school: Relations between social responsibility and academic achievement. Review of Educational Research, 61, 1-24.

Wentzel, K.R. (2005). Peer relationships, motivation, and academic performance in school. In A.J. Elliot \& C.S. Dweck (Eds.), Handbook of competence and motivation (pp. 279-317). New York: Guilford Press. 